\title{
EDITORIAL
}

\section{No harm, no benefit: should we give up with neurally adjusted ventilatory assist?}

\author{
Paolo Navalesi $i^{1,2,3^{*}}$ and Federico Longhini ${ }^{2}$
}

๑) 2016 Springer-Verlag Berlin Heidelberg and ESICM

Mechanical ventilation is a frequent reason for admitting a patient to the intensive care unit (ICU) and is therefore one of the most common forms of treatment we use in our ICU daily practice. We apply it for varying reasons, the most frequent being an episode of acute respiratory failure (ARF) that may be caused by a variety of conditions [1]

In the most severely ill patients, such as those with severe ARF and acute respiratory distress syndrome (ARDS), we generally prefer replacing entirely patient's respiratory muscle activity to improve gas exchange without further damaging the lung, by means of controlled modes of mechanical ventilation. Some of us believe volume-targeted modes serve better, some others consider pressure-targeted modes superior: both beliefs are right and wrong as no large randomized trials ever compared these forms of controlled ventilation, while a recent meta-analysis, including small studies often of limited quality, did not find any significant differences in any clinical outcome [2].

When controlled modes are no longer strictly necessary, most of us prefer switching to modes of partial ventilatory assistance, thereby allowing the patient's spontaneous activity to trigger the ventilator. By increasing patient contribution to ventilation, we aim primarily to avert the risk of ventilator-induced diaphragmatic dysfunction and reduce administration of sedatives. In principle, while with the controlled modes the patient must be adapted to the mechanical breath, which is achieved by suppressing his or her respiratory drive by sedatives and sometimes paralysing agents, with the modes of partial support it is the machine that must adapt to the patient's own breathing activity and this interaction between patient and ventilator assumes crucial

\footnotetext{
*Correspondence: paolo.navalesi@med.uniupo.it

1 Department of Translational Medicine, Università del Piemonte Orientale "Amedeo Avogadro", Novara, Italy

Full author information is available at the end of the article
}

importance. The interest for this aspect has grown up in recent years, as a poor interaction leading to asynchrony between patient effort and ventilator assistance has been associated with worse outcomes, such as longer durations of mechanical ventilation [3-5] and ICU stay $[4,5]$, higher rate of tracheotomy [4], and lower probabilities of survival [4] and home discharge [5].

Over the past decades, many technical aspects of ventilators have improved and several modes of partial support have been developed to facilitate patient-ventilator interaction. The extreme advance of this technological development is represented by the so-called proportional modes, i.e., proportional assist ventilation and neurally adjusted ventilator assist (NAVA), allowing the patient to completely drive the ventilator [6]. NAVA, in particular, has the unique feature of triggering and driving the ventilator assistance through the electrical activity of the diaphragm (EAdi).

After introduction of NAVA in clinical use less than a decade ago, the studies on this mode increased every year, consistently showing, compared to the conventional modes of partial support using pneumatic signal, i.e., flow, volume and airway pressure, an improved patientventilator interaction, resulting in smaller delays between patient demand and support delivery, reduced risk of over-assistance, and lower rates of asynchrony [7]. Again, although many of us consider these physiological benefits of clinical importance, whether they really translate into better outcomes remains to be proved.

In a recent article in Intensive Care Medicine, Demoule et al. attempt to address this issue with a multicenter randomized clinical trial (RCT) comparing NAVA with a broadly used mode of partial support, pressure support ventilation (PSV), in 118 patients in the early phase of weaning from mechanical ventilation [8]. As expected, compared to PSV, NAVA lowered the rate of asynchrony. However, NAVA neither increased the probability of remaining in a mode of partial support during the first

\section{Springer}


$48 \mathrm{~h}$ (primary endpoint) nor decreased length of stay and mortality or increased ventilator-free days on day 14 and 28. Although in the NAVA group the ventilator-free days on day 7 were higher and the patients receiving postextubation noninvasive ventilation fewer, these results clearly configure the scenario of a negative trial.

Should we consider this study the tombstone of NAVA? RCTs are fundamental to determining the value of new treatments over current practice. In a recent multicenter RCT, early application of high frequency oscillation in adults with moderate-to-severe ARDS not only failed to reduce but actually increased in-hospital mortality, as compared to a protective ventilation strategy [9]. As Demoule et al. remark, though this RCT fails to find differences in efficacy between NAVA and PSV, it indicates that NAVA is safe and feasible over a prolonged period of time [8].

Because despite fewer asynchronies NAVA does not improve patients' outcomes, some would argue these findings show that patient-ventilator asynchrony is a marker of severity due to poor respiratory function, rather than a cause of increased morbidity. However, as proposed by the Demoule et al. [8], NAVA could be beneficial only in specific patient groups with severe asynchrony and problematic weaning; therefore, as their study includes patients with ARF regardless of the precipitating factor, the effects of NAVA could be somewhat diluted.

In addition, the expertise in mechanical ventilation may affect the rate of asynchrony. Demoule et al. [8] enrolled their patients in academic centers highly experienced in mechanical ventilation, which may not reflect the "real world". This also makes it possible, as suggested by the authors, that the rate of controls not remaining in PSV is too low to prevent additional improvement. Further to this observation, the protocol for the PSV arm led to application of moderate support levels, protecting against the risk of over-assistance and the occurrence of ineffective efforts [10], which also makes NAVA less likely to outperform PSV. In fact, tidal volumes were no different between the two modes (around $7 \mathrm{ml} / \mathrm{kg}$ ), while the rate of ineffective efforts in the PSV group was quite low. Finally, while in daily practice no signal indicating patient effort is available during PSV, EAdi was disclosed for both groups of patients, which may have influenced the physicians' behavior relating to PSV settings.

In the light of all these considerations, we do not believe the 118 patients of this RCT have erected the tombstone of NAVA. They rather tell us that, although safe, NAVA should probably not be used extensively for all ICU patients with ARF, at least in centers with a high expertise in mechanical ventilation.

\section{Author details}

${ }^{1}$ Department of Translational Medicine, Università del Piemonte Orientale "Amedeo Avogadro", Novara, Italy. ${ }^{2}$ Anesthesia and Intensive Care Medicine, Sant'Andrea Hospital, Vercelli, Italy. ${ }^{3}$ CRRF Mons. L. Novarese, Moncrivello (VC), Italy.

\section{Compliance with ethical standards}

\section{Conflicts of interest}

Disclosure of potential related to the present article: Dr. Navalesi's research laboratory has received equipment and grants from Maquet Critical Care. He also received honoraria/speaking fees from Maquet Critical Care. Dr. Longhini has no personal conflict to disclose. Disclosure of potential conflicts of interest unrelated to the present article: Dr. Navalesi's research laboratory has received equipment and grants from Draeger, Fisher and Paykel, Biotest, and Intersurgical S.p.A. He also received honoraria/speaking fees from Draeger, Breas, Philips, Resmed, and Hill-rom. Dr. Navalesi contributed to the development of the helmet Next, whose licence for patent belongs to Intersurgical S.p.A., and receives royalties for that invention. Dr. Longhini has no personal conflict to disclose.

Received: 28 July 2016 Accepted: 1 August 2016

Published online: 30 September 2016

\section{References}

1. Esteban A, Frutos-Vivar F, Muriel A, Ferguson ND, Penuelas O, Abraira V, Raymondos K, Rios F, Nin N, Apezteguia C, Violi DA, Thille AW, Brochard L, Gonzalez M, Villagomez AJ, Hurtado J, Davies AR, Du B, Maggiore SM, Pelosi P, Soto L, Tomicic V, D'Empaire G, Matamis D, Abroug F, Moreno RP, Soares MA, Arabi Y, Sandi F, Jibaja M, Amin P, Koh Y, Kuiper MA, Bulow HH, Zeggwagh AA, Anzueto A (2013) Evolution of mortality over time in patients receiving mechanical ventilation. Am J Respir Crit Care Med 188:220-230

2. Rittayamai N, Katsios CM, Beloncle F, Friedrich JO, Mancebo J, Brochard $L$ (2015) Pressure-controlled vs volume-controlled ventilation in acute respiratory failure: a physiology-based narrative and systematic review. Chest 148:340-355

3. Chao DC, Scheinhorn DJ, Stearn-Hassenpflug M (1997) Patient-ventilator trigger asynchrony in prolonged mechanical ventilation. Chest 112:1592-1599

4. Thille AW, Rodriguez P, Cabello B, Lellouche F, Brochard L (2006) Patientventilator asynchrony during assisted mechanical ventilation. Intensive Care Med 32:1515-1522

5. de Wit M, Miller KB, Green DA, Ostman HE, Gennings C, Epstein SK (2009) Ineffective triggering predicts increased duration of mechanical ventilation. Crit Care Med 37:2740-2745

6. Navalesi P, Costa R (2003) New modes of mechanical ventilation: proportional assist ventilation, neurally adjusted ventilatory assist, and fractal ventilation. Curr Opin Crit Care 9:51-58

7. Navalesi P, Longhini F (2015) Neurally adjusted ventilatory assist. Curr Opin Crit Care 21:58-64

8. Demoule A, Clavel M, Rolland-Debord C, Perbet S, Terzi N, Kouatchet A, Wallet F, Roze H, Vargas F, Guerin C, Dellamonica J, Jaber S, Brochard L, Similowski T (2016) Neurally adjusted ventilatory assist as an alternative to pressure support ventilation in adults: a French multicentre randomized trial. Intensive Care Med. doi:10.1007/s00134-016-4447-8

9. Ferguson ND, Cook DJ, Guyatt GH, Mehta S, Hand L, Austin P, Zhou Q, Matte A, Walter SD, Lamontagne F, Granton JT, Arabi YM, Arroliga AC, Stewart TE, Slutsky AS, Meade MO (2013) High-frequency oscillation in early acute respiratory distress syndrome. N Engl J Med 368:795-805

10. Thille AW, Cabello B, Galia F, Lyazidi A, Brochard L (2008) Reduction of patient-ventilator asynchrony by reducing tidal volume during pressuresupport ventilation. Intensive Care Med 34:1477-1486 